\title{
The Positive and Negative Affect of Authoritarian Personality among Female University Students
}

\author{
Reem Khamees Mahdia , Athraa Esmail Zaidan ${ }^{b},{ }^{a, b}$ University of Baghdad - \\ Women's Studies Center, 'areem.m@wsc.uobaghdad.edu.iq, \\ bdr.athraaesmail2020@gmail.com
}

The purpose of the study is to determine whether positive and negative affect are related to a type of authoritarian personality. Participants $(\mathrm{N}=$ 150) were female university students in Baghdad. The authors applied INPANAS scale to measure the positive and negative affect, and F scale to measure the authoritarian personality. Results: first, the sample had a positive affect on the authoritarian personality, but not a negative affect, second, there is a significant weak correlation between PA, NA, and authoritarian personality. Conclusion: The cognition affects on authoritarian personality more than the emotions do. In light of the new scientific challenges; this type of personality requires more research to reach a clear explanation for this personality in the future.

Key words: Affect, Personality, Authoritarian, Female, Students

\section{Introduction}

Watson and Tellegen 1985 proposed a model for two mood dimensions, usually called positive and negative affect, (Watson et.al., 1988). Positive Affect PA is a the tendency to experience positive emotions and feelings through positive interactions with life and others (Scott, 2020). While Negative Affect NA is a stable variable by experiencing negative and unpleasant emotions and feelings (Paulus \& Zvolensky, 2017). PA and NA are two mood factors, and high distinctive dimensions that can be uncorrelated factors, and can measure as a state or trait. PA is a factor of pleasure and high PA reflects on emotion, energy, interest and joy whereas low PA reflects fatigue (Watson et.al., 1988).

NA is a factor of sadness, it is a risk factor for mental health and a disposition to experience negative feelings as fear, anger, and sadness. It correlated with many psychological disorders, 
and also contributed to personality disorders. Prospective studies have found NA to be predictable lately of mental health problems and hypertension (Paulus \& Zvolensky, 2017). Fredrickson (2004) has developed and built theory to explain the nature of positive emotions. According to Fredrickson, positive emotions broaden the mental processes like attention, thinking, and actions. People who experience positive affect in many situations appear to have unique types of thinking, flexibility, openness to information, and a variety of acceptance (Fredrickson, 2004). Fredrickson has shown that negative emotions lead to many tendencies, called momentary thought-action repertoire (Lino, 2020), and that means while people feel bad, they tend to experience specific actions such as to escape in fear, or attach in anger. In good feelings, they experience a broadening of their momentary thought-actions repertoire, and that leads to build and pursue types of thinking and actions like play, savour and explore (Fredrickson \& Branigan, 2005).

Nelson (2009) suggested that positive affect correlated with cultural empathy, openmindedness, and flexible thinking; while neutral or negative affect promoted less emotional empathy (Nelson, 2009).

Many studies (Zanon et.al., 2013; Gross et.al., 1998) showed a strong relationship between feelings, cognition and many dimensions of personality like neuroticism, extraversion, and levels of empathy (Nelson, 2009).

The relationship between emotions and other elements like ideology also play a role in personality traits. Tomkins $(1963,1965)$ has suggested the polarity model. According to this model the right-wing ideology shows a highly ideoaffective tendency to have an attitude toward many topics as rearing of children, science and religion, and have a high percentage in positive and negative affect, while the left-wing shows the opposite attitude (Butler, 2000).

People with left-wing tendencies always show positive affect (joy, excitement), and are more expressive, they also feel negative (shame and distress). People with right-wing tendencies respond quickly to negative affect (contempt, disgust and anger). Tompkins (1965) suggested the role of socialisation was to produce left-right children (Stone, 1986, p.691). Authoritarianism or intolerance is "an extreme feature of general right-wing ideology", (Butler, 2000).

An authoritarian personality is " a personality pattern reflecting a desire for security, order, power, and status, with a desire for structured lines of authority, a conventional set of values or outlook, demand for unquestioning obedience, and a tendency to be hostile toward or use as scapegoats individuals of a minority or non-traditional groups" (Dictionary, 2020). This type of personality correlates excessively with authority defence, aggression toward others out of similar groups, and tough commitment to its cultural conventions, (Pettigrew, 2011).

During the last years of Nazi Germany, two Marxist psychoanalysts, Wilhelm Reich and Erik Fromm proposed models related to the "structure of authoritarian personality" in an attempt to 
explain the reason for why the lower middle social class was so affected by Adolf Hitler (Samelson, 2001).

According to Fromm, fascism effected the individual's illusion of the importance of security within the broader group. Therefore, of course the individual will resort to giving up their own freedom for the group leader to which they belong. Since capitalism has failed to realise the existential importance of the modern individual, it will be the target of fascism. Fromm illustrated his theory for Mein Kampf, which reflects the fascist's view, or the psychology of Hitler, (Billing, 1978).

In 1950, the main publication "The Authoritarian Personality" appeared and resulted from two German refugees (Theodore Adorno and Ellen Frankl-Brunswick) and two American social psychologists (Daniel Levinson and Nevette Sanford) at the University of California Berkeley campus. The publication firmly grounded the idea in social sciences. The F-scale (invented by Adorno to measure authoritarianism and inspired by the word fascism) has been used to develops over 2,000 published research papers, (Pettigrew, 2011). Adorno and Brunswick, Levinson \& Sanford proposed in 1950 a style of personality that they initially called the "Potentially Fascistic Individual", (Adorno et.al., 1982; Billig, 1978) What contributed to the emergence of this term was the nature of current events in the early twentieth century beginning with the emergence of fascism in Italy, World War II and the emergence of anti-Semitism in Germany. This made the fascist individual more inclined to anti-Semitism and to antidemocratic policies, which the author has made a subject of study (Adorno et.al., 1993).

Rokeach (1960) developed dogmatism scale which measured the authoritarian personality and intolerance by measuring the level of openness and closed nature of mind or belief system, (Rokeach, 2015).

\section{The Socialisation of Authoritarian Personality:}

Oesterreich (1974) in his study has showed the connection between overprotecting, dominant, and controlling parents and authoritarian personality. This parental behaviours makes children dependent and suffer from lack of independence, which in turn makes him or her an individual that cannot cope with stressful situations, or problem solve. Also the culture contributes to developing authoritarianism, or it is a result of many "highly differentiated societies", (Oesterreich, 2005 , p.286).

Diana Baumrind (1971, 1973) classified parenting styles and one of them was authoritarian.According to Baumrind authoritarian parents - confirmed controlling, dominant, obedience, respect of authority, conservation of order and traditions, children always showed little social interaction and independence but to so they had to be aggressive or tough (Lesser, 1985). 
A growing body of literature suggested that authoritarianism is influenced by genetics. Genetic and personality traits correlated with social attitudinal measures, belief dynamics and authoritarian processes. The importance of socialisation appeared in Altemeyer work that cited a high correlation between scores of child and parents on his scale RWA. There is a large amount of evidence that disagrees that the social affect on authoritarianism that came from large scale twin study, (Zschau, 2010). Waller, Kojetin ,Bouchard, Lykken and Tellegan (1990) indicated the possibility of genetics in religious interest, and social attitude in part influenced by genetics, and parent-child correlation reflected the impact of the environment (Waller et.al., 1990).

\section{Personality Core Features:}

The authoritarian individual is characterised by authority, aggression, conservative thinking, and reactionary behaviour, (Kurbanov et.al., 2018). The basic feature for authoritarianism is authoritarian submission, authoritarian aggression and conventionalism (Chien, 2016). Fromm (1931) researched syndromes of conventionalism, authoritarian submission, authoritarian aggression, and power and toughness, in 1936, he added superstitiousness as a syndrome. In 1941, he added destructiveness and rigid conformism. He described authoritarian people as having a weak ego, offset by a strong super ego, and repressed identity by external authorities. Fromm (1941) "described authoritarianism as a possibility to (escape from freedom) to search on security", (Baars \& Sheepers, 1993 , pp.347-350). Although their aggression, but it seems a" weak aggression " as described by Karen Horney and Fromm (1941) the authoritarians flight to security through over aggression, they suffer from low self-esteem and they live in a society they can cope with. They are not aggressive all the time but feel hostility (Oesterreich , 2005).

Aim of the study: the study measured :

-The score of positive and negative affect.

- The score of authoritarian personality.

- The correlation between both of the scores above.

\section{Methods:}

Method Approach: Survey method .

Participants: Participants were 150 female university undergraduate students with an age 1830 with range 24 years old in Baghdad City.

Tools: Self - Report Measures: the authors apply two of scales:

Positive and Negative Affect Scale: The authors applied international PANAS scale IPANAS - SF (Thompson, 2007) to measure the emotional experience during the previous week, (Karim et.al. , 2012). The scale had 10 items and each item is rated from (very slightly or not at all "coded as 1 " to extremely" coded as 5 ") . 
Authoritarian Personality Scale: the authors applied Fascism scale F Scale (Adorno 1947), (The F Scale, 2018). To measure the authoritarian personality. The scale had 30 items which rated from (disagree strongly "coded as 1 " to agree strongly " coded as 6 ") with nine dimensions" Conventionalism, Authoritarian Submission, Authoritarian Aggression, Superstition and Stereotypy, Power and Toughness, Anti-Interception, Destructiveness and Cynicism, Projectivity, and Sex " .

To examine the validity, the authors calculated Construct Validity by using Pearsons correlation coefficient to measure items related to the total score of the F Scale and PANAS Scale, T-Calculated $>1.97(\mathrm{P}<.05)$, that means all the items of PANAS scale were statistical significant. Also the authors calculated items related to scale's dimensions, T-Calculated $>1.97$ ( $\mathrm{P}<.05)$, that means all the items correlation with dimensions were statistically significant.

Translation Validity: the authors presented the scale to an professional in the English language to translate it into Arabic language and then re-translate it into English language, to examine the extent of the compatibility of the two translations . A suitable copy has been reached for the Iraqi community environment.

To measure the reliability, the authors calculated the internal consistency of F Scale, which was determined by Cronbach's $\alpha$ Coefficient. It was 0.81 for F Scale, and for PA and NA Scale was 0.67. Split Half Reliability for F scale was 0.64 by Pearson correlation coefficient and correct by Spearman - Brown formula is 0.71 , Split Half Reliability for PA - NA scale was 0.63 and correct by Spearman - Brown formula is 0.70 .

\section{Results:}

By applying SPSS Ver. 24 in this study, the mean is $16.75>15$, the sample had a positive affect. The mean is $11.2<15$, the sample did not have a negative affect.

Table (1): mean and the standard deviations for PA \& NA

\begin{tabular}{|lll|}
\hline Dimension & M. & S.D. \\
PA & 16.7467 & 3.40782 \\
NA & 11.2000 & 3.95444 \\
\hline
\end{tabular}

The mean of Authoritarian Personality is $147.09>105$, which means the sample had the authoritarian personality. 
Table (2): T-test for one sample

\begin{tabular}{|lllllll|}
\hline Mean & $\begin{array}{l}\text { standard } \\
\text { deviation }\end{array}$ & $\begin{array}{l}\text { Calculated } \\
\text { T Value }\end{array}$ & $\begin{array}{l}\text { Hypothesized } \\
\text { mean }\end{array}$ & d.f. & $\begin{array}{l}\text { Tabulated } \\
\text { T value }\end{array}$ & Signification \\
147.09 & 12.02 & 42.89 & 105 & 149 & 1.97 & Significant \\
\hline
\end{tabular}

\section{PA, NA and authoritarian personality Correlation:}

By applied Pearson correlation coefficient to measure the correlation between PA and authoritarian personality, the authors found that $\mathrm{r}=-.23, \mathrm{p}<.05$, the correlation was negative but weak. Pearson correlation coefficient to measure the correlation between NA and was correlate with authoritarian personality, $\mathrm{r}=.19, \mathrm{p}<.05$, the correlation was positive but very weak.

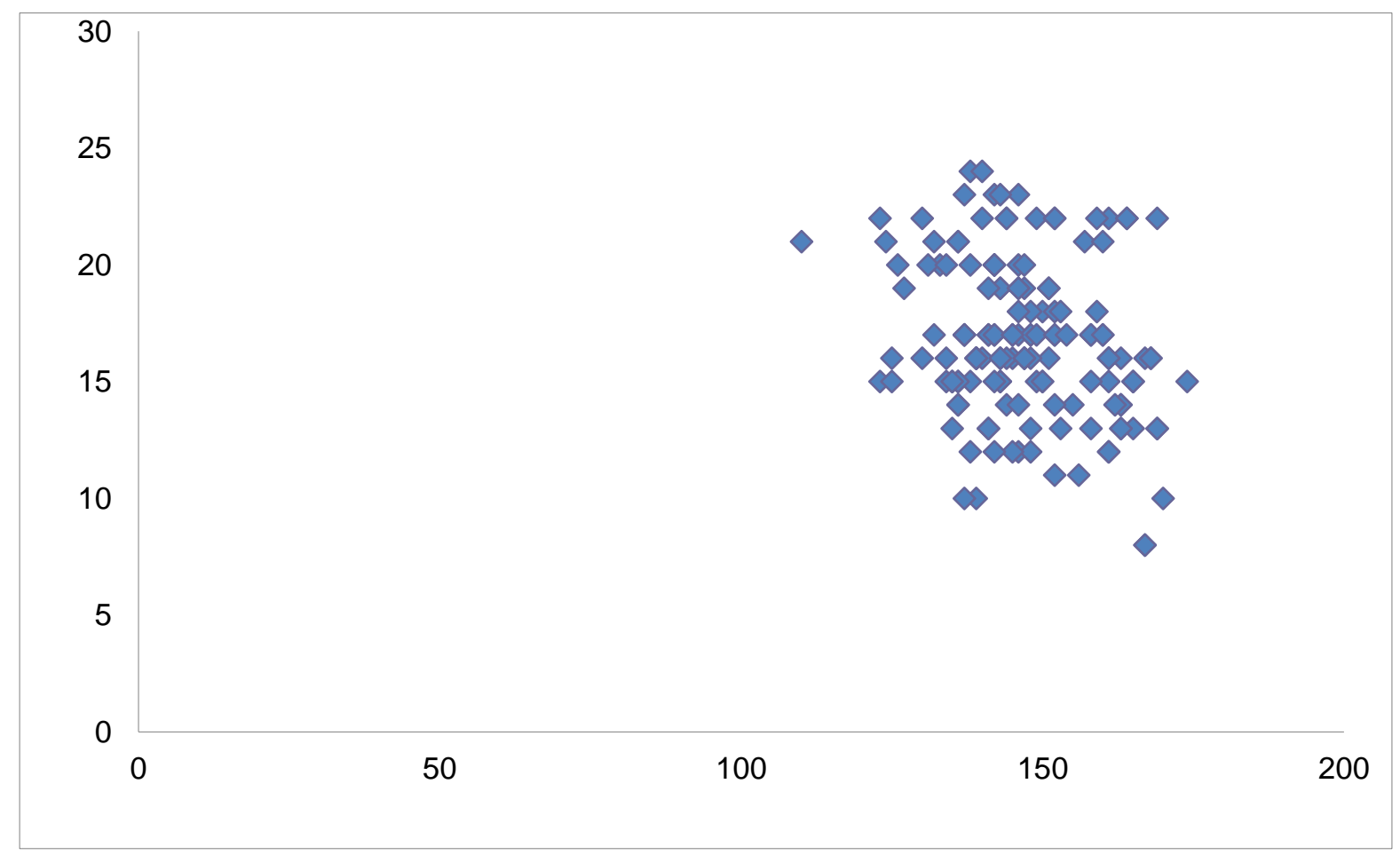

Figure (1): Relationship between scores on PA items/ PANAS scale and Authoritarian Personality scale, $r=-.23$ 


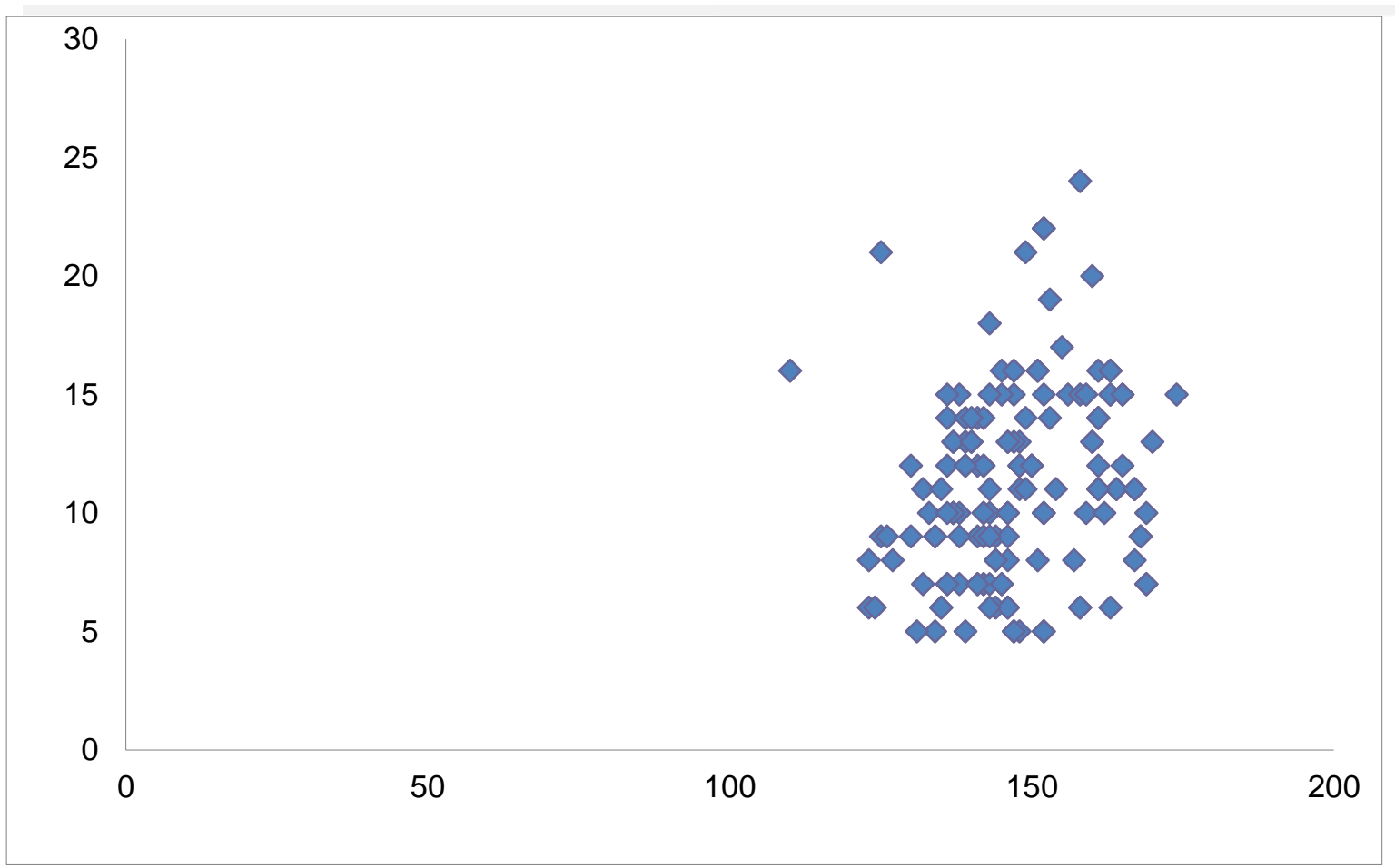

Figure (1): Relationship between scores on NA items / PANAS scale and Authoritarian Personality scale, $r=.19$

\section{PA, NA and authoritarian personality dimensions:}

PA was correlated negatively with Conventionalism -0.175, Authoritarian Aggression -0.176, Anti-Intraception -0.313, Destructiveness and Cynicism -0.165, and Projectivity -0.197, and was not correlated with Authoritarian Submission, Superstition and Stereotypy, Power and Toughness, and Sex.

Table (3): The correlation between each dimension of authoritarian personality and positive affect, $p<.05, \mathrm{df}=\mathbf{1 . 9 7}$

\begin{tabular}{|llc|}
\hline Dimensions & $\begin{array}{l}\text { T-value for } \\
\text { coefficient test }\end{array}$ & $\begin{array}{c}\text { correlation } \\
\text { Conventionalism }\end{array}$ \\
Authoritarian Submission & 2.16 & $\begin{array}{l}\text { correlation } \\
\text { coefficient }\end{array}$ \\
Authoritarian Aggression & 0.17 & $0.175-$ \\
Anti-Intraception & 2.18 & 0.014 \\
Superstition and Stereotypy & 4.01 & -0.176 \\
Power and Toughness & 1.9 & -0.313 \\
Destructiveness and Cynicism & 0.72 & -0.154 \\
\hline
\end{tabular}




\begin{tabular}{|lcc|}
\hline Projectivity & 2.44 & -0.197 \\
Sex & 1.38 & -0.113 \\
\hline
\end{tabular}

NA was correlated positively with Superstition and Stereotypy 0.345, and Power and Toughness 0.282 , and was correlated negatively with Destructiveness and Cynicism - 0.038 and Sex -0.021 , and was not correlated with other dimensions.

Table (4): The correlation between each dimension of authoritarian personality and negative affect $, \mathrm{p}<.05, \mathrm{df}=\mathbf{1 . 9 7}$

\begin{tabular}{|lll|}
\hline Dimensions & $\begin{array}{l}\text { T-value } \\
\text { correlation } \\
\text { coefficient test }\end{array}$ & $\begin{array}{l}\text { for } \\
\text { correlation } \\
\text { coefficient }\end{array}$ \\
Conventionalism & 0.99 & 0.081 \\
Authoritarian Submission & 0.98 & 0.08 \\
Authoritarian Aggression & 0.85 & 0.07 \\
Anti-Intraception & 1.04 & 0.085 \\
Superstition and Stereotypy & 4.47 & 0.345 \\
Power and Toughness & 3.58 & 0.282 \\
Destructiveness and Cynicism & 0.46 & -0.038 \\
Projectivity & 0.23 & 0.019 \\
Sex & 0.26 & -0.021 \\
\hline
\end{tabular}

\section{Discussion:}

It is clear that authoritarian personality is not strongly related to emotional effectiveness. In this study, authoritarian personality correlated a negative weak relationship with PA $(r=-.23)$, and positive very weak relationship with NA $(r=.19)$

This result supports the previous studies (Van Hiel \& Kossowska , 2006; Butler, 2000) and consistent to the nature of authoritarian people, authoritarian personality tends to be more aggressive and intolerant.Nelson (2006) found that positive affect promotes anopen mind not a closed mind (Nelson, 2006). Although the correlation was negative with PA, there is a correlation between PA and F Scale dimensions. This can be explained by re-studying this type of personality in societies that suffering from a societal intellectual fanatical, especially in the countries of the Middle East where intellectual and ideological conflicts abound. Perhaps this explains the reason for the positive activity being linked to this type of personality in light of being in environments corresponds to the nature of the characteristics of the authoritarian 
personality. Butler (2000) in his study N.3 measured the relationships among PA, NA, and life satisfaction with authoritarian personality. He found that life satisfaction was the only significant correlation with authoritarianism which was in the opposite direction for their opinion, and explained the result by the differences between authoritarian and nonauthoritarian people by unconsciousness emotions, which means it can't be measured by selfreporting (Butler, 2000). Altemeyer (1996) has suggested that authoritarianism had a low level of negative feeling like fear, and that explains why most authoritarians are more aggressive and intolerant against out-group people, (Altemeyer, 1996). This may explain the low correlation between NA and authoritarian personality.

The correlation of PA with the conventionalism, authoritarian aggression, anti-intraception, destructiveness and cynicism and projectivity is statistically significant. The correlation was negative, and corresponded to the nature of positive affect. Altemeyer (1996) in his study his right-wing authoritarianism scale RWA, found that males were more dominant than females but not in high RWA scores, (Altemeyer, 1996). The correlation with other dimensions (authoritarian submission, superstition and stereotypy, power and toughness, and sex) requires more studies.

Tomkins (1965) predicted the correlation between right-wing ideology (authoritarian personality) and negative affect (Butler, 2000, p.9). The correlation of NA with the conventionalism, authoritarian aggression, anti-intraception, and projectivity was not statistically significant. NA was negatively correlated with destructiveness and cynicism, and sex. NA is a factor for hostility not aggression, especially for the female sample. The sex variable reduced the probability of psychical aggression and NA, (Donahue et.al., 2014). The sex items in the scale were three (item number: 13-16-29) and that was not enough to measure the sex attitude for the sample. The only statistical significance was the correlation between NA and superstition and stereotypy, and power and toughness. This result consisted of a study that showed that a superstition significant correlated with emotional maladjustment and irrational associations (Maller \& Lundeen, 1934), and with stereotypy \& prejudice, (Whitley, 1999). Other studies have shown that NA reflects anger, hostility, and upset, (Stringer, 2013; Sierra et.al., 2019).

\section{Conclusion}

In recent decades, the problem of the tendency to aggressive behaviours and feeling depressed,anger and hostility among university students has become common. Authoritarianism is a factors that contributes to increasing the violence especially against minorities. In this study, the authors examined the relationships between positive affect, negative affect, and authoritarian personality. The female students' sample had authoritarian personality and PA but did not have NA. In a previous study (Butler, 2000), authoritarianism did not correlate with emotional affect. The emotional differences between authoritarian and non-authoritarian people may appear in specific situations. Karen Stenner in her book "In The 
Authoritarian Dynamic" indicated that authoritarian people think and live normally like everyone but in normative situations that threaten their beliefs, they will merge what they believe and change their behaviours, (Winter, 2013). The cognition affects on authoritarian personality more than the emotions do. Van Hiel, De keersmaecker, Onraet, Haesevoets, Roets \& Fontaine 2019 study found that right-wing attitudes strongly correlated with cognitive abilities and negatively correlated with emotional abilities, (Van Hiel et.al., 2019). Altemeyer (1996) has suggested that authoritarian people are contradictory thinkers, and that supports the idea of the cognitive roots of this type of personality (Butler, 2000). In light of the new scientific challenges this type of personality requires more research to obtain a clear explanation for this personality in the future.

Declaration of Conflicting Interests: The authors declared that they had no conflicts of interest concerning their authorship or the publication of this article.

Novelty/Originality of this study: As far as the authors are concerned, there is only a small number of research on analysing the relationship between authoritarian personality dimensions and the nature of feelings and emotions. This scientific study is the first of its kind in the Arabic region that concerns female attitudes toward authoritarianism. The current research attempted to study this relationship (authoritarianism and emotions) in the Arabic environment.

Acknowledgment: The authors thank Assistant Prof. Dr. Sabah Manfi, Faculty of Administration and Economics / University of Baghdad to help the authors in statistical procedures for this study. 


\section{References:}

Adorno, T., Brunswik, E. F., Levinson, D. J., \& Sanford, R. N. (1982). The Authoritarian Personality. U.S.A.: W.W. Norton \& Company, Inc.

Altemeyer, B. (1996). The other authoritarian personality. political psychology, 86-107.

Authoritarian Personality. (2020). Retrieved july 10, 2020, from https://www.dictionary.com: https://www.dictionary.com/browse/authoritarian-personality

Baars, J., \& Sheepers, P. (1993). Theoritical and Methodological Foundatios of the Authoritarian Personality. Journal of the History of the Behavioral Sciences , 29 (4), 345-353. https://doi.org/10.1002/1520-6696(199310)29:4<345::AID$\underline{\mathrm{JHBS} 2300290405>3.0 . \mathrm{CO} ; 2-\mathrm{L}}$

Billig, M. (1978). Fascists: A Social Psychological View of the National Front (New Edition ed.). London, U.K.: Academic Press.

Butler, J. C. (2000). Personality and Emotional Correlates of Right-Wing Authoritarianism. Social Behavior and Personality: an international journal , 28 (1), 1-14. DOI: https://doi.org/10.2224/sbp.

Chien, C.-L. (2016). Beyond Authoritarian Personality: The Culture-Inclusive Theory of Chinese Authoritarian Orientation. Front. Psychol. https://doi.org/10.3389/fpsyg.2016.00924

Donahue, J. J., Goranson, A. C., McClure, K. S., \& Van Male, L. M. (2014). Emotion dysregulation, negative affect, and aggression: A moderated, multiple mediator analysis. Personality and Individual Differences , 70, 23-28. https://doi.org/10.1016/i.paid.2014.06.009

Elizabeth Scott. (2020, march). Retrieved from verywellmind.com: https://www.verywellmind.com/positive-affect-and-stress-3144628

Fredrickson, B. L. (2004). The broaden-and-build theory of positive emotions. The Royal Society, 359, 1367-1377. doi: 10.1098/rstb.2004.1512

Fredrickson, B. L., \& Branigan, C. (2005). Positive emotions broaden the scope of attention and thought-action repertoires. Cogn Emot , 19 (3), 313-332. doi: $10.1080 / 02699930441000238$

Gross, J. J., Sutton, K. S., \& Ketelaar, T. (1998). Relations Between Affect and Personality: Support for the Affect-Level and Affective-Reactivity Views. Personality and Social Pyscology Bulletin, 24 (3), 279-290. https://doi.org/10.1177/0146167298243005

Karim, J., Weiszb, R., \& Rehman, S. U. (2011). International positive and negative affect schedule short-form(I-PANAS-SF): testing for factorial invariance across cultures. Procedia Social and Behavioral Sciences , 2016-2022. doi:10.1016/j.sbspro.2011.04.046

Kurbanov, R. A., KUZNETSOV, V. V., CHELPACHENKO, T. V., VITVITCKAIA, L. A., POLYAKOVA, L. Y., \& BELYALOVA, A. M. (2018). Relationship between authoritarianismand tendency to dominate ininterpersonal communication ofuniversity students. Revista Espacios , 39 (20). ISSN 07981015

Lesser, H. (1985). The Socialization of Authoritarianism in Children. The High School Journal , $68(3), 162-166$. 
Lino, C. (2020, 6 10). Broaden-and-Build Theory of Positive Emotions (+PDF). Retrieved from positivepsychology.com: https://positivepsychology.com/broaden-build-theory/

Maller, J., \& Lundeen, G. E. (1934). Superstition and emotional maladjustment. The journal of Educational Research , 27 (8), 592-617.

Nelson, D. W. (2006). Feeling good and open-minded: The impact of positive affect on cross cultural empathic responding. The Journal of The Positive Psychology , 4 (1), 53-63. https://doi.org/10.1080/17439760802357859

Oesterreich, D. (2005). Flight into Security:A New Approach and Measure of The Authoritarian Personality. Political Psychology, 26 (2), 275-297.

Pattigrew, T. F. (2011). The Authoritarian Personality. Oxford, U.K.: Blackwell.

Paulus, D. J., \& Zvolensky, M. J. (2017). Negative Affectivity. (V. Z. Hill, \& T. K. Shackelford, Eds.) Encyclopedia of personality and individual differences . DOI: https://doi.org/10.1007/978-3-319-28099-8_1255-1

Rokeach, M. (2015). The OPen and Closed Mind. Martino Publishing.

Samelson, F. (2001). Authoritarian Personality: History of the Concept. International Encyclopedia of the Social \& Behavioral Sciences, 967-970.

Sierra, J. O., Bañuelos, M., de Albéniz, A. P., Molina, B. L., \& Pedrero, E. F. (2019). The study of Positive and Negative Affect in children and adolescents: New advances in a Spanish version of the PANAS. (A. Blanch, Ed.) PloS One, 14 (8). https://doi.org/10.1371/journal.pone.0221696

Stone, W. F. (1986). Personality and Ideology: Empirical Support for Tomkins' Polarity Theory. political psychology , 7 (4), 689-708. https://doi.org/10.2307/3791209

Stringer, D. M. (2013). Negative Affect. Encyclopedia of Behavioral Medicine .

The F Scale. (1999 , 2018). Retrieved 2019, from www.anesi.com: https://www.anesi.com/fscale.htm

Thompson, E. (2007). Development and Validation of an Internationally Reliable Short-Form of the Positive and Negative Affect Schedule (PANAS). Journal of Cross-Cultural Psychology, 227-242. https://doi.org/10.1177/0022022106297301

Van Hiel, A., \& Kossowska, M. (2006). Having few positive emotions, or too many negative feelings? Emotions as moderating variables of authoritarianism effects on racism. Personality and Individual Differences , $40 \quad$ (5), 919-930. https://doi.org/10.1016/i.paid.2005.09.014Get

Van Hiel, A., De keersmaecker, J., Onraet, E., Haesevoets, T., Roets, A., \& Fontaine, J. R. (2019). The relationship between emotional abilities and right-wing and prejudiced attitudes. Emotion , 19 (5), 917-922. https://doi.org/10.1037/emo0000497

Waller, N. G., Kojetin, B. A., Buchard, T. J., Jr., Lykken, D. T., \& Tellegen, A. (1990). Genetic and Environmental influenced on relegious interests, attitudes, and values. Psychological Science , 1 (2), 138-142. 10.1111/i.1467-9280.1990.tb00083.x

Watson, D., Clarck, A., \& Carey, G. (1988). positive and negative affectivity and their relation to anxiety and depressive disorders. journal of abnormal psychology, 97 (3), 346-333. https://doi.org/10.1037/0021-843X.97.3.346 
Whitley, B. ,Jr. (1999). Right-wing authoritarianism, social dominance orientation, and prejudice. Journal of Personality and Social Psychology, 77 (1), 126-134. https://doi.org/10.1037/0022-3514.77.1.126

Winter, R. (2013). Power and Fear: Explaining the Authoritarian Personality. ResPublica Journal of Undergraduate Research , 18 (1), 1-8. http://digitalcommons.iwu.edu/respublica/vol18/iss1/6

Zanon, C., Bastianello, M. R., Pacico, J. C., \& Hutz, C. S. (2013). Relationships Between Positive and Negative Affect and the Five Factors of Personality in a Brazilian Sample . Paidéia (Ribeirão Preto) .

Zschau, T. (2010, July). The Authoritarian Cosmos: Complexity, Elective Affinities and The Thermodynamics of The Self. Retrieved July 10, 2020, from shareok.org: https://shareok.org/bitstream/handle/11244/7017/Department\%20of\%20Sociology 25 .pdf?sequence $=1$ 